\title{
A prospective evaluation of the availability and utility of the Ambulance Call Record in the emergency department
}

\author{
Natalie Cram, MD*; Shelley McLeod, $\mathrm{MSc}^{\dagger \neq}$; Michael Lewell, MD*; Matthew Davis, MD, MSc*
}

\section{ABSTRACT}

Objective: To determine how often the Ambulance Call Record (ACR) was available to emergency department (ED) physicians and whether it contained information that changed the ED management of patients.

Methods: This was a prospective cohort study of adult patients transported to one of two tertiary care centre EDs. Physicians completed a data collection form for each patient regarding $A C R$ availability and the perceived value of the ACR. This study began shortly after the implementation of a new electronic ACR (eACR) handover process (Round 1). To control for any confounding factors related to this new eACR handover process, the study was repeated 6 months after its implementation (Round 2).

Results: Total of 869 forms were collected: 545 in Round 1, and 324 in Round 2. The ACR was available at first physician assessment for 82 (15.7\%) patients in Round 1, and 76 (24.4\%) patients in Round $2(\Delta 8.7 \%, 95 \% \mathrm{Cl}: 3.1 \%, 14.5 \%)$. The ACR was available at some point during patients' ED stay for 154 (28.9\%) patients in Round 1, compared to 111 (34.5\%) patients in Round $2(\Delta 5.6 \%, 95 \% \mathrm{Cl}: 0.0 \%, 12.1 \%)$. When the ACR was available for a patient $(n=265)$, physicians believed that information in the ACR changed their treatment plan in 76 $(28.8 \%)$ cases.

Conclusion: Physicians who review the ACR believe that the ACR contains relevant information that may influence patient management; however, physicians commonly manage patients without reviewing the ACR.

\section{RÉSUMÉ}

Objectifs: L'étude visait à déterminer dans quelle mesure les enregistreurs d'appels d'ambulance (EAA) étaient à la disposition des médecins et si les renseignements fournis influaient sur le traitement des patients au service des urgences (SU).

Méthode: II s'agit d'une étude de cohorte prospective, composée d'adultes transportés à l'un des deux SU de soins tertiaires. Les médecins ont rempli, pour chacun des malades, un formulaire de collecte de données relativement à la présence ou non d'un EAA et à la perception de la valeur de ce type d'appareil. L'étude a commencé peu de temps après la mise en œuvre d'un processus de transfert de soins à l'aide $d^{\prime} u n$ nouvel EAA électronique ( ${ }^{\text {re }}$ étape). Six mois après la mise en œuvre du processus de transfert de soins ( $2^{\mathrm{e}}$ étape), l'étude a été reprise afin que soit éliminé tout facteur parasite lié à I'utilisation du nouvel EAA électronique.

Résultats: Au total, 869 formulaires ont été recueillis : 545 au cours de la $1^{\text {re }}$ étape et 324 au cours de la $2^{\mathrm{e}}$ étape. Un EAA était disponible à la première évaluation médicale de $82(15,7 \%)$ patients au cours de la $1^{\text {re }}$ étape et de $76(24,4 \%)$ patients au cours de la $2^{\mathrm{e}}$ étape (écart $[\Delta]$ 8,7 \%; IC à $95 \%: 3,1 \%-14,5 \%$ ). Par ailleurs, les médecins avaient la possibilité d'écouter I'EAA à tout moment durant le séjour des patients au SU dans $154(28,9 \%)$ cas au cours de la $1^{\text {re }}$ étape et dans $111(34,5 \%)$ cas au cours de la $2^{\mathrm{e}}$ étape $(\Delta 5,6 \%$; IC à $95 \%: 0,0 \%-12,1 \%)$. Enfin, les médecins étaient d'avis que, lorsqu'il était possible d'écouter les EAA $(n=265)$, les renseignements fournis avaient modifié le plan de traitement de 76 patients $(28,8 \%)$.

Conclusions: Les médecins qui écoutent les EAA estiment que les appareils fournissent des renseignements utiles, susceptibles de modifier le traitement des patients; toutefois, les médecins traitent généralement les patients sans écouter les EAA.

Keywords: Ambulance Call Record, Emergency Medical Services, paramedic handover, patient care record

\section{INTRODUCTION}

Emergency department (ED) nurses, and occasionally physicians, receive verbal handover from paramedics as part of their transfer of care from emergency medical services (EMS). In the loud and chaotic environment of an ED, effective communication during handover can be a challenge. It has been demonstrated that this

From the *Southwest Ontario Regional Base Hospital Program, Western University, London, ON; ${ }^{\dagger}$ Department of Family and Community Medicine, University of Toronto, Toronto, ON; and the ${ }^{\ddagger}$ Schwartz/Reisman Emergency Medicine Institute, Mount Sinai Hospital, New York, NY.

Correspondence to: Dr. Natalie Cram, Southwest Ontario Regional Base Hospital Program, London Health Sciences Center, 4056 Meadowbrook Dr., Unit 145, London, ON N6L 1E5; Email: ncram2011@meds.uwo.ca 
is a high risk activity and that important information is lost in the exchange between EMS providers and ED staff. ${ }^{1-5}$

Effective transfer of information from paramedics to ED staff may be impeded by multiple factors. It is difficult for paramedics to accurately report all pertinent patient information via a brief verbal handover. Benner et al. demonstrated that EMS reported only $44 \%$ of discrete patient data points to physicians during handover. ${ }^{1}$ Information that could assist the ED physician in providing expedient and appropriate care, but is missing or unavailable, is known as information gaps. These "gaps" can lead to longer patient ED lengths of stay. ${ }^{4}$

A further barrier to effective EMS handover is poor physician recall. A previous study identified that physicians accurately recalled only $36 \%$ of the paramedic verbal report. ${ }^{2}$ Similarly, research conducted in two large Birmingham EDs demonstrated that only $56.6 \%$ of the information given by ambulance crews during handover was accurately retained by ED staff. ${ }^{3}$ Furthermore, in a study examining information loss in EMS handover of trauma patients, it was found that only $72.9 \%$ of the information relayed by paramedics to the receiving team was documented, with prehospital hypotension, pulse rate, and Glasgow Coma Scale failing to be received by the trauma team in the majority of cases when it was transmitted by paramedics. ${ }^{6}$

The Ambulance Call Record (ACR) is a standardized document that is completed by paramedics for each patient contact. It is used to record pertinent clinical history, physical exam findings, past medical history, medications, allergies, vital signs, and prehospital medical treatments. It is believed that the ACR may provide ED physicians with valuable patient information because, oftentimes, physicians do not receive handover directly from paramedics or do not retain the information provided by paramedics. ${ }^{7,8}$ The ACR may also serve as a reliable reference in the case that information was omitted by paramedics, or forgotten by physicians or nursing staff during verbal handover.

Despite the National Association of EMS Physician's (NAEMSP) position that the complete EMS patient care report must be available to the receiving facility within a clinically relevant period of time, not all EMS systems require that the ACR be completed prior to crews responding to their next patient care call. ${ }^{9}$ As a result, ED physicians often assess, treat, and determine disposition of patients without the knowledge of information contained within the ACR. When valuable information relevant to making patient care decisions is not available to the ED physician in real time, but will be contained in the final medical record, there exists the potential for risks related to patient safety and medico-legal.

The purpose of this study was to determine how often the ACR was available to ED physicians for patients transported by EMS, and to document whether the ACR contained information that changed the ED management of these patients.

\section{METHODS}

\section{Study design}

This was a prospective cohort study of all adult patients ( $\geq 18$ years) transported by the ambulance to one of two tertiary academic EDs in London, ON (combined annual census 125,000$)$. The study was conducted over two 4-week time periods (Round $1=$ July 24 - August 21, 2012; Round 2 = February 19 - March 19, 2013) to control for any confounding factors related to the implementation of a new electronic ACR (eACR) in April of 2012. The study protocol was approved by the Health Sciences Research Ethics Board at Western University.

\section{Population and setting}

This study was completed in London, $\mathrm{ON}$, which has a population of approximately 366,000 . London is a part of Middlesex County, where EMS is provided by Middlesex London Emergency Medical Services (MLEMS). MLEMS has approximately 40,000 patient contacts per year. At the study centres, paramedics complete standardized eACRs on a laptop computer. Completed ACRs are then electronically faxed from the laptop to the ED and added to the patient's chart by ED clerical staff. Although paramedics are encouraged to complete the ACR before they are cleared to leave the ED, the Ministry of Health and Long Term Care Document Standards mandates that copies of completed ACRs be distributed within 48 hours of a completed call in the studied EMS system. ${ }^{10}$

\section{Selection of participants}

Patients were eligible for participation in this study if they were 18 years of age or older and arrived by 
ambulance. Patients were excluded if they were being transferred directly to the care of a specialty service, or if they met criteria for STEMI or stroke bypass.

Prior to study initiation, an awareness campaign was launched to educate paramedics, nurses, physicians, and ED clerical staff about the study in order to achieve maximum identification and enrolment of patients. Methods of disseminating this information included multiple emails, study posters displayed in the EDs and paramedic bases, and verbal announcements at academic rounds. Throughout the study, email reminders were sent to all involved in order to maximize enrolment.

\section{Data collection and processing}

Paramedics identified eligible patients upon their arrival to the ED and handed a paper-based data collection form to the triage or receiving nurse to be attached to the patient chart. Registration clerks, nurses, and accepting physicians were also asked to attach a data collection form to the charts of eligible patients in cases where paramedics had not identified them.

All ED physicians were invited to participate in this study. Physicians were asked to complete the data collection form after finishing their initial assessment of the patient. The form included questions regarding the availability of the ACR during initial patient assessment, and the perceived value of the ACR to change patient management or provide support for diagnosis and disposition. The availability of the ACR was determined by the physician (i.e., could the ACR physically be located with the patient chart?). If the ACR was not available, physicians were asked if and how they believed the ACR could have changed or expedited patient care. The collected data were entered into a standardized excel worksheet by a trained research assistant. The response rate was based on the number of forms collected, each representing an individual patient encounter. The number of ambulances that arrived to the ED during the study period was collected from the hospital's department of Decision Support.

\section{Sample size and analysis}

The initial study goal was to collect data during two 2 -week time periods. It was estimated that $325 \mathrm{ED}$ patients were seen each day in the two EDs, with approximately $20 \%$ arriving by ambulance. It was estimated that 65 patients would be enrolled each day, resulting in a total of 1820 patients enrolled throughout the entire study period. Due to low patient enrolment, each study period was extended to 4 weeks.

Data were entered directly into a study-specific Microsoft Excel database (Microsoft Corporation, Redmond, WA). Descriptive statistics were summarized using means and standard deviations, medians, and interquartile ranges or proportional differences where appropriate. Statistical analyses were conducted using Stata 13.0 (StataCorp LP, College Station, TX).

\section{RESULTS}

During Rounds 1 and 2, 2234 and 2232 patients, respectively, were brought to the EDs by ambulance; 869 forms were collected over the two 4-week study periods: 545 (24.4\%) in Round 1, and 324 (14.5\%) in Round 2. When individual questions on the form were unanswered by physicians, these "non-responses" were excluded from analysis (Table 1). The ACR was available at first physician assessment for 82 (15.7\%) patients in Round 1, versus $76(24.4 \%)$ patients in Round $2(\Delta 8.7 \%, 95 \%$ CI: $3.1 \%, 14.5 \%)$. The ACR was available at some point during patients' ED stay for $154(28.9 \%)$ patients in Round 1, compared to 111 $(34.5 \%)$ patients in Round $2(\Delta 5.6 \%, 95 \%$ CI: $0.0 \%$, 12.1\%) (Figure 1).

When an ACR was available $(\mathrm{n}=265$ : $\mathrm{R} 1=154$; $\mathrm{R} 2=111$ ), physicians reported that the information changed or altered their treatment plan in $76(28.8 \%)$ cases, as described in Table 2 . When a patient's ACR was not available $(\mathrm{n}=590), 63.9 \%(\mathrm{n}=375)$ of physicians reported that it could have provided valuable information, such as patient history and vital signs (Table 3). In 411 (50.5\%) cases, the ACR was unavailable and the physician did not receive verbal handover from a nurse or paramedic. Physicians received both verbal handover and an ACR in only $56(6.9 \%)$ cases.

In Round 1, when the ACR was unavailable and a physician assessment time was documented $(\mathrm{n}=349)$, a research assistant was able to match a fax time to each individual ACR for 295 ACRs; 107 (36.3\%) of the unavailable ACRs had been faxed to the ED at least 10 minutes prior to the physician's initial assessment (PIA). If these faxed ACRs had been added to the patients' charts in a timely manner, ACR availability at PIA could be increased from $15.7 \%(82 / 522)$ to $36.2 \%$ $(82+107 / 522)$. 


\begin{tabular}{|c|c|c|c|}
\hline Question & Round 1 & Round 2 & Total \\
\hline Total number of forms collected & 545 & 324 & 869 \\
\hline ACR available at first physician assessment & $\begin{array}{c}82 / 522 \\
(15.7 \%)\end{array}$ & $\begin{array}{c}76 / 312 \\
(24.4 \%)\end{array}$ & \\
\hline ACR available at some point during ED stay & $\begin{array}{l}154 / 533 \\
(28.9 \%)\end{array}$ & $\begin{array}{l}111 / 322 \\
(34.5 \%)\end{array}$ & \\
\hline When the ACR was available: & 154 & 111 & 265 \\
\hline The physician reported information changed or altered treatment. & $\begin{array}{l}52 / 153 \\
(34 \%)\end{array}$ & $\begin{array}{c}24 / 111 \\
(21.6 \%)\end{array}$ & $\begin{array}{c}76 / 264 \\
(28.8 \%)\end{array}$ \\
\hline When the ACR was not available: & 379 & 211 & 590 \\
\hline The physician believed the ACR could have provided valuable information. & $\begin{array}{l}248 / 375 \\
(66.1 \%)\end{array}$ & $\begin{array}{l}125 / 209 \\
(59.8 \%)\end{array}$ & $\begin{array}{l}373 / 584 \\
(63.9 \%)\end{array}$ \\
\hline ACR unavailable and no verbal handover & $\begin{array}{c}263 / 510 * \\
(51.6 \%)\end{array}$ & $148 / 304^{\dagger}(48.7 \%)$ & $\begin{array}{l}411 / 814 \\
(50.5 \%)\end{array}$ \\
\hline ACR available and physician received verbal handover & $\begin{array}{c}38 / 510^{*} \\
(7.5 \%)\end{array}$ & $\begin{array}{c}18 / 304^{\dagger} \\
(5.9 \%)\end{array}$ & $\begin{array}{l}56 / 814 \\
(6.9 \%)\end{array}$ \\
\hline $\begin{array}{l}\text { ACR unavailable, physician assessment time documented, and fax time documented } \\
\text { Faxed to the ED at least } 10 \text { minutes prior to PIA }\end{array}$ & $\begin{array}{c}295 \\
107 / 295(36.3 \%)\end{array}$ & & \\
\hline
\end{tabular}

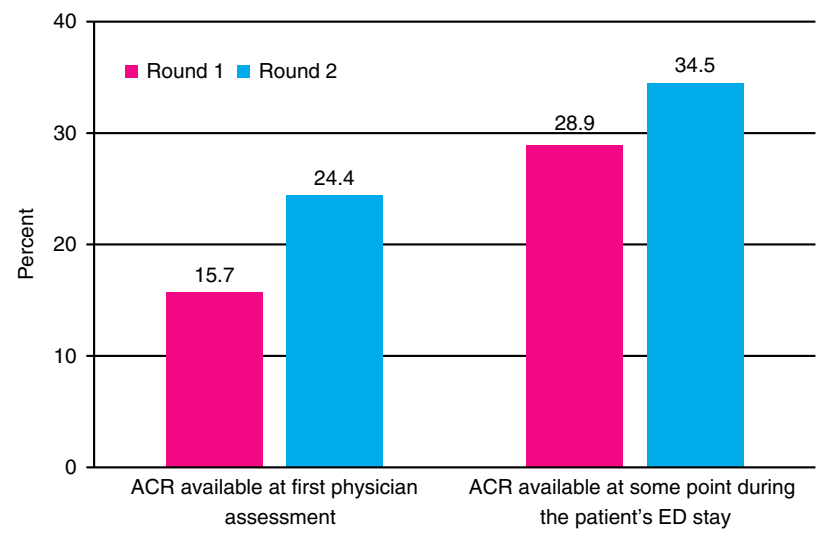

Figure 1. The availability of ACRs to ED physicians.

\section{DISCUSSION}

The findings of our study validate the importance of the prehospital information contained in the ACR. While previous research has demonstrated the general value of the ACR, and the fact that physicians perceive the ACR as an important tool, we were able to show that physicians believed that the ACR changed management in $28.8 \%$ of specific patient encounters. ${ }^{11,12}$

In our study, physicians did not receive an ACR or verbal handover from a nurse or paramedic in half of patients (50.5\%), highlighting the possible loss of valuable
Table 2. Physician perception of how the ACR changed patient management when it was available

\begin{tabular}{lc|}
$\begin{array}{l}\text { Physician perception of how the ACR } \\
\text { changed ED management }\end{array}$ & $\begin{array}{c}\text { Number* }(n=70 \\
\text { responses) }\end{array}$ \\
\hline Medical therapy & $37(52.9 \%)$ \\
Lab investigation & $28(40.0 \%)$ \\
Imaging investigation & $20(28.6 \%)$ \\
Outpatient referral & $7(10.0 \%)$ \\
Inpatient referral & $3(4.3 \%)$ \\
Other & $10(14.3 \%)$ \\
When an ACR was available, $76(28.8 \%)$ physicians believed that it changed patient \\
management; 70 (R1 = 48; R2 22$)$ of these physicians responded regarding how \\
ED management was changed. \\
*Physicians could choose more than one response for each patient encounter.
\end{tabular}

prehospital information, which could result in improper or inadequate workups, treatments, and disposition decisions. Although physicians regard prehospital information from paramedics as relevant and important to patient care, handover is often incomplete. Yonge et al. (2008) found that $79 \%$ of emergency physicians described information from paramedic handover as "useful" or "very useful," but $67 \%$ believed that key information was sometimes, often, or always missing from the verbal report. ${ }^{11}$ Additionally, introduction of a structured handover format does not improve physician recall, thus stressing the importance of the ACR as a record of information. , $^{2,13}$ 


\begin{tabular}{|c|c|}
\hline $\begin{array}{l}\text { Perceived valuable information in } \\
\text { ACR }\end{array}$ & $\begin{array}{l}\text { Number }{ }^{*}(n=364 \\
\text { responses) }\end{array}$ \\
\hline Vital signs & $252(69.2 \%)$ \\
\hline Patient history & $263(64.8 \%)$ \\
\hline Prehospital rhythm analysis & $109(29.9 \%)$ \\
\hline $\begin{array}{l}\text { Prehospital interventions and } \\
\text { treatments }\end{array}$ & $144(39.6 \%)$ \\
\hline
\end{tabular}

A large survey of the American College of Emergency Physicians (ACEP) physicians demonstrated that $89 \%$ of physicians felt that prehospital records were either "very important" or "important" to their ED practice, but were usually unavailable at the time of medical decision-making. ${ }^{12}$ In keeping with this finding, $81.1 \%$ of patients in our study did not have an ACR available to the treating physician at the time of initial assessment, and $69.5 \%$ did not have an ACR available at any point during ED care. This finding is contrary to the NAEMSP position that the complete EMS patient care report must be made available to the receiving facility within a clinically relevant period of time. ${ }^{9}$ Given that investigations, treatments, and disposition decisions are made during a patient's ED stay, it can be inferred from this position statement that the ACR should be available to ED physicians during this "clinically relevant" time period.

When the ACR is unavailable, the physician must rely on verbal handover of patient information. In a busy tertiary ED, physicians are often only available to receive EMS verbal handover for resuscitative patients with an obvious disposition. As a result, the ACR may have the greatest potential to change the management and disposition of less acute patients. ED physicians do not usually receive verbal handover for these patients, and access to documentation of key prehospital historical and clinical findings could significantly alter the patient's disposition. For example, a patient with abnormal vital signs on initial assessment or subtle electrocardiogram (ECG) changes captured on the prehospital 12-lead could be discharged home with significant unrecognized pathology if the ACR containing this information is not available to the physician. In a retrospective study, the prehospital ECG influenced the ED management of nearly one in four patients. ${ }^{14} \mathrm{~A}$ follow-up prospective study revealed that
$12.5 \%$ of prehospital ECGs demonstrated abnormalities not captured on the initial ED ECG, and changed the ED management of $18.5 \%$ of patients. ${ }^{15}$ The potential to change a patient's disposition ultimately increases the value of the ACR in this population. In a study looking at information gaps in ED visits, Stiell et al. demonstrated that one of the two most common gaps was patient history. ${ }^{4}$ Our findings indicate that when the ACR is unavailable, ED physicians believed that the patient history provided in the ACR may have been valuable in guiding appropriate care to the patient in nearly $65 \%$ of cases.

In cases where the ACR was present, physicians believed that it contained information that changed or altered their treatment plan in $28.8 \%$ of cases. When the ACR was unavailable, $63.9 \%$ of physicians believed that it could have provided useful information such as patient history and vital signs. A specific example where physicians believed that the ACR could provide valuable information was for patients that were unable to provide an accurate history, that is, patients who were intoxicated, cognitively impaired, or suffering from dementia. Additionally, in $39.6 \%$ of patient encounters, the ED physician perceived that the ACR would have been beneficial to inform the physician of prehospital interventions and treatments provided by paramedics. In keeping with this finding, a study by Waldron and Sixsmith showed that physician awareness of prehospital procedures and medications was lacking, and the use of a verbal hand-off report still resulted in significant loss of information. ${ }^{16}$

There was an increase in availability of the ACR in Round 2 compared to Round 1. This modest increase may have been due to paramedics becoming more efficient at using the new eACR system, resulting in faster ACR completion, or the improved retrieving of faxed ACRs from the printer by clerical staff. The process by which ACRs were made available to the physician may have impacted this study. We were able to determine a specific fax time for each of the patient ACRs during Round 1. When fax times were compared to the PIA time, it was discovered that 107 of the unavailable ACRs had been faxed to the printer at least 10 minutes prior to PIA. These ACRs could have been available to the physician if they had been retrieved more promptly from the printer. Based on these numbers, ACR availability at PIA in Round 1 could have been more than doubled. Since the completion of this project, this finding has resulted in a quality 
improvement project within our system to improve ACR availability.

Not all EMS systems require that the ACR be completed prior to crews responding to their next patient care call. In our EMS system, copies of completed ACRs are mandated by the Ministry of Health to be distributed within 48 hours of a completed call. ${ }^{10}$ This is long after the treating physician is required to make a disposition decision. Based on the results of this study, the utility and medico-legal implications of documenting patient information without providing it to the physician who is treating and ultimately dispositioning the patient should be further explored, because failure to provide essential prehospital information may adversely affect patient care and patient safety.

With the potential to alter a patient's treatment plan in nearly one third of cases, the development of digital strategies to ensure that ACRs are available to the treating ED physician should be considered.

\section{LIMITATIONS}

There was an overall study enrolment of approximately $19.5 \%(869 / 4466)$ of eligible patients. Significant communication efforts were employed to increase enrolment, but the completion of data collection form by physicians was low. Numerous factors contributed to this. This study was an unfunded project, and it was not feasible to have a research assistant in the ED to actively recruit patients and encourage physicians to participate. With a high volume of patients arriving by ambulance, physicians likely experienced response fatigue. In a busy department, filling out a 2-minute survey multiple times during a shift can become onerous because attending staff have numerous competing demands occurring simultaneously. The high volume of rotating residents and medical students through the ED also created a challenge. Unless the house staff asked their attending to fill out the research form during their initial patient assessment, it is theorized that the ED attending would less likely go out of his or her way to fill out the forms for those patients seen by their house staff. In the study centre, there are usually multiple research projects being conducted simultaneously that compete for a physician's time and may have contributed to the lower than expected response rate. There was a sizeable difference in the number of patients enrolled in each collection period given the relatively stable number of ambulances arriving to the ED. This difference may be related to study fatigue on the part of paramedics, nurses, and physicians.

Given the low response rate, the authors recognize that there is a significant risk of bias. We did not collect any physician information on the data collection tool and therefore cannot comment on characteristics of our physician responders. It is unknown whether ED physicians were more likely to report that the ACR contained clinically useful information because of a positive response bias. Similarly, when the ACR was unavailable, physicians were asked to hypothesize the potential utility of the ACR, and it is unknown whether ACR utility may have been overestimated because of the ongoing study.

This study included adult patients only. In the study centre, there is an independent pediatric ED, and the number of ambulance calls for pediatric patients is relatively small. Given the challenges of engaging a separate department to participate in the study, we chose to focus on adults. Examining the perceived utility of the ACR in pediatric patients is a potential area of future research.

Finally, given that this study was conducted in a single EMS system and two tertiary EDs, the results may not be generalizable to other systems. EMS systems using paper ACRs avoid the technological errors inherent to an ACR delivery process that relies on computers and fax machines. However, paper ACRs have their own intrinsic drawbacks such as poor legibility, the risk of losing the paper hard copy, and need for manual delivery to the hospital after completion. ${ }^{12}$ Additionally, in our system, there are human factors and errors involved with ED clerical staff being responsible for retrieving the faxed ACRs from the printer and adding them to the patient chart in a timely manner. The ideal ACR delivery system would likely involve an eACR that could be uploaded to the patient's e-health record system and viewed by the treating physician in real-time. Unfortunately, at the present time, these two systems are not linked at our centre.

\section{CONCLUSION}

A small number of emergency physicians who review the ACR during patient management believe that the ACR contains clinically relevant information that may change or influence the ED management of patients. However, the majority of physicians manage patients 
without reviewing the ACR. Taking steps to increase ACR availability at the time of initial assessment may increase physician review rates. Future research with physicians employing higher ACR utility rates is needed to explore whether this implementation change results in improved quality and safety of patient care.

\section{Competing interests: None declared.}

\section{SUPPLEMENTARY MATERIAL}

To view supplementary material for this article, please visit http://dx.doi.org/10.1017/cem.2016.362

\section{REFERENCES}

1. Benner J, Hilton J, Carr G, et al. Correspondence: information transfer from prehospital to ED health care providers. Am 7 Emerg Med 2008;26:233-44.

2. Scott L, Brice J, Baker C, et al. An analysis of paramedic verbal reports to physicians in the emergency department trauma room. Prehosp Emerg Care 2003;7(2):247-51.

3. Talbot R, Bleetman A. Retention of information by emergency department staff at ambulance handover: do standardised approaches work? Emerg Med 7 2007;24: 539-42.

4. Stiell A, Forster AJ, Stiell IG, et al. Prevalence of information gaps in the emergency department and the effect on patient outcomes. CMA7 2003;169(10):1023-8.

5. Evans SM, Murray A, Patrick I, et al. Assessing clinical handover between paramedics and the trauma team. Injury 2010;41:460-4.
6. Carter AJE, Davis KA, Evans LV, et al. Information loss in emergency medical services handover of trauma patients. Prehosp Emerg Care.

7. Yong G, Dent AW, Weiland TJ. Handover from paramedics: observations and emergency department clinician perceptions. Emerg Med Australas 2008;20:149-55.

8. Jenkin A, Abelsen-Mitchell N, Cooper S. Patient handover: time for a change? Accid Emerg Nurs 2007;15:141-7.

9. NAEMSP Position Statement. Transfer of patient care between EMS providers and receiving facilities. Prehosp Emerg Care 2014;18(2):305.

10. Ministry of Health and Long Term Care. Ambulance Service Documentation Standards; 2000. Available at: https://www. hsnsudbury.ca/portalen/Portals/23/Ontario\%20Ambulance $\% 20$ Documentation $\% 20$ Standards.pdf?ver $=2016-02-29$ 152040-183.

11. Yong G, Dent A, Weiland T. Handover from paramedics: observations and emergency department clinician perceptions. Emerg Med Australas 2008;20(2):149-55.

12. Bledsoe B, Wasden C, Johnson L. Electronic Prehospital Records are often unavailable for emergency department medical decision making. West 7 Emerg Med 2013;14(5): 482-8.

13. Owen C, Hemmings L, Brown T. Lost in translation: maximizing handover effectiveness between paramedics and receiving staff in the emergency department. Emerg Med Australas 2009;21:102-7.

14. Davis M, Dukelow A, McLeod S, et al. The utility of the prehospital electrocardiogram. CFEM 2011;13(6):372-7.

15. Davis M, Lewell M, McLeod S, et al. A prospective evaluation of the utility of the prehospital 12-lead electrocardiogram to change patient management in the emergency department. Prebosp Emerg Care 2015;18(1):9-14.

16. Waldron R, Sixsmith DM. Emergency physician awareness of prehospital procedures and medications. West 7 Emerg Med 2014;15(4):504-10. 